\title{
MEDICINA DE PRECISIÓN: EL FUTURO DE LA MEDICINA
}

\author{
PRECISION MEDICINE: THE FUTURE OF MEDICINE
}

Aly Gallo', Jhony A. De La Cruz -Vargas $2, a, b, c$

La secuenciación del genoma humano allá por el año 2001 generó la más grande revolución de conocimiento en salud del siglo XXI, gracias a este acontecimiento hoy podemos saber con claridad como funcionan los sistemas biológicos. Por otro lado, la implementación de plataformas diagnósticas cada vez más sofisticadas y sensibles que adicionadas al desarrollo de la industria farmacéutica, en los últimos 18 años, han generado un cambio de paradigma llamado: Medicina de Precisión, situación que hace cada vez más lejano pensar en una medicina como la que se practica actualmente, basada en el ensayo-error, donde el objetivo es un diagnóstico y tratamiento dirigido contra la sintomatología.

En ese orden de ideas, imaginemos que en este momento algún colega médico, está tratando a uno de sus pacientes y para diagnosticarlo ha solicitado una serie de herramientas de apoyo como imágenes o análisis clínicos, cumpliendo con una Guía de Práctica Clínica que aunada a su experiencia lo llevará (si es necesario) a diseñar y prescribirle un tratamiento sintomático y modificador, buscando que los fármacos interactúen con un objetivo específico en la red biológica subyacente a la enfermedad, impactando directa o indirectamente en la progresión de ésta y en la persona; hasta allí todo bien, a esto nosotros denominamos "terapia convencional", una práctica aceptada y validada por nuestro sistema de salud.

Sin embargo, el crecimiento poblacional, la mutación de los vectores que ocasionan la enfermedad, los estilos de vida, el estrés, el medioambiente inestable que nos rodea, la investigación médica y otras variables incontrolables, transitan por rutas desalineadas, ocasionando paulatina y dramáticamente un colapso en la sostenibilidad de los sistemas de salud actuales, sobre todo en países como el nuestro. Esta realidad, exige continuar y adoptar lo que ahora es una tendencia mundial cada vez más extendida y definitivamente imparable, es decir, ampliar el estudio de nuestra biología, desde el punto de vista molecular y dentro de ese campo: la genómica, cuyo avance ha desencadenado una revolución en la investigación, para comprender incluso los sistemas biológicos más complejos, utilizando la secuenciación de ADN de próxima generación (NGS) y la bioinformática para ensamblar y analizar la función y la estructura de genomas completos, haciendo una "medicina de ojos abiertos".

El desafío en nuestra región exige proponer un cambio de paradigma en la ciencia y la medicina, para que utilizando la plataforma tecnológica más adecuada y avanzada, procesar muestras, no de forma visual y cuantitativa, sino, estudiando sus polimorfismos y asociando estos resultados a una historia clínica digital con información abierta y continua de datos clínicos relevantes actualizados con la mayor frecuencia posible, además, información de estilo de vida, interacción con el medio ambiente, a fin de conseguir y validar de manera más precisa y asertiva el tipo de respuesta que una persona puede tener a las múltiples posibilidades de manejo existentes para su enfermedad actual o potencial, en un formato de costo-efectividad, mediante una labor multidisciplinaria y deseablemente multisectorial.

\footnotetext{
Director General de ARC-PER

2Director General del INICIB, URP.

Especialista en Oncologia Medica.

Maestria en Investigacion Clinica.

Doctorado en Medicina.
}

Citar como: Aly Gallo, Jhony A. De La Cruz -Vargas. Medicina de precisión: El futuro de la medicina. [Editorial]. Rev. Fac. Med. Hum. 2018;18(2):11-12. DOI 10.25176/RFMH.v18.n2.1279 
Todo esto ha evolucionado los sistemas terapéuticos empleando metodologías de estratificación y de personalización, lo que nos lleva a la aplicación de Medicina de Precisión, que es un nuevo modelo de atención médica personalizada que tiene como base el empleo sistematizado de toda la información que hemos descrito (big data), para aplicar intervenciones terapéuticas y/o preventivas en aquellos pacientes que se beneficiarán de las mismas, evitando posibles efectos secundarios, y brindando la oportunidad a los pacientes que no se beneficiarán, de acceder a otro tipo de tratamiento, en el momento más oportuno, evitando gastos innecesarios, aumentando la calidad de vida y la tasa de sobrevida, como en el caso de enfermedades catastróficas como el cáncer, donde se aplica más intensivamente.

ARC-PER, ha logrado la concurrencia de los elementos básicos para abordar este inmenso reto, faltando, obtener data genómica propia de nuestra población y sus diferentes etnias, almacenar y procesar las grandes cantidades de datos que se producirán para optimizar protocolos de tratamiento y desarrollar los necesarios, y otras tareas igual de relevantes, sin embargo, debemos advertir que el proyecto es tan grande y los objetivos tan estructurados que otro de los grandes retos será lograr la articulación nacional e internacional que permita avances significativos, todos tenemos un rol que asumir y un aporte que hacer: el futuro es hoy.

Contribuciones de autoría: Los autores participaron en la generación, redacción y aprobación final del artículo original.

\section{Financiamiento: Autofinanciado.}

Conflicto de interés: El autor declara no tener conflicto de interés en la publicación de este artículo.

Recibido: 09 de enero del 2017

Aprobado: 16 de febrero del 2017

Correspondencia: Aly Gallo

Dirección: Velasco Astete Nro. 1952 Alborada, Santiago de Surco

Celular: 993888643

Correo:alygallolopez@gmail.com

\section{REFERENCIAS BIBLIOGRÁFICAS}

1. Noguera Solano, Ricardo y Ruiz Gutierrez Rosaura (2000). El Proyecto Genoma Humano. Ciencias 58, abril-junio 14-13.

2. Schork, Nicholas. Personalized Medicine: Time for one person trials. Nature, April 29, 2015.

3. Byrnes Nanette, Woyke Elizabeth, Weintraub Arlene. Precision Medicine. MIT Technology Review Business Reports. September 2016.

4. Genomics England, Genomics England and the 100,000 genomes Project. Narrative 2017.

5. Lancet Editorial. Personalised Medicine in UK. Published On Line
December 21, 2017 http://dx.doi.org/10.1016/SO140-6736(17)33261-0. 6. IQVIA Institute for Human Data Science. Upholding the Clinical Promise of Precision Medicine: Current Position and Outlook. Institute Report, May 22, 2017.

7. IQVIA Institute for Human Data Science. Global Oncology Trends 2107 Advances, Complexity and Cost. Institute Report, May 31, 2017.

8. Fundación Instituto Roche. Propuesta de Recomendaciones para una Estrategia Estatal de Medicina Personalizada de Precisión: Anticipando el futuro, Acelerando los cambios. www.institutoroche.es. Mayo 2017.

\section{Indizado en: latindex}

http://www.latindex.org/latindex/ficha?folio=14280<smiles>C1CC2CC1C2</smiles>
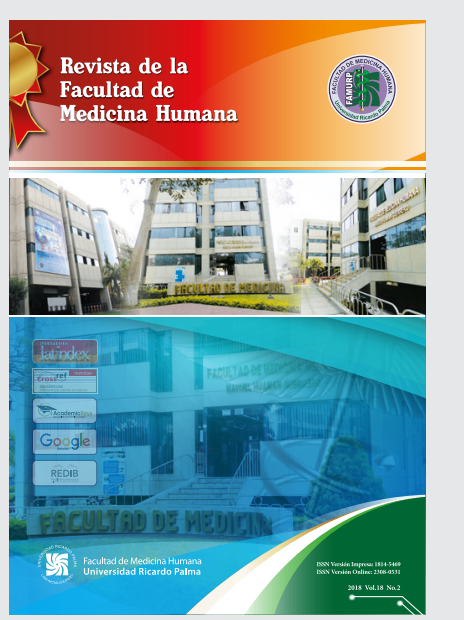